\title{
Variabilidade no cpDNA em Manilkara huberi, espécie sob manejo sustentável na Amazônia brasileira
}

\author{
Vânia Cristina Rennó Azevedo(1), Milton Kanashiro(2), Dario Grattapaglia ${ }^{(1)}$ e Ana Yamaguishi Ciampi ${ }^{(1)}$
}

\begin{abstract}
(1)Embrapa Recursos Genéticos e Biotecnologia, Caixa Postal 02370, CEP 70770-900 Brasília, DF. E-mail: azevedovcr@cenargen.embrapa.br, aciampi@cenargen.embrapa.br, dario@cenargen.embrapa.br (2)Embrapa Amazônia Oriental, Caixa Postal 48, CEP 66095-100 Belém, PA. E-mail: milton@cpatu.embrapa.br
\end{abstract}

\begin{abstract}
Resumo - O objetivo deste trabalho foi avaliar a existência de estruturação genética matrilinear em maçaranduba (Manilkara huberi). Foram avaliados 481 indivíduos adultos de M. huberi, distribuídos em 200 hectares de uma população natural na Floresta Nacional do Tapajós, Belterra, PA, e 88 regenerantes, com base na análise de nove microssatélites de cloroplasto e, de 96 indivíduos adultos, selecionados aleatoriamente na área de 200 ha, foi realizado o seqüenciamento de três regiões não codificadoras de cpDNA. Não foi detectado polimorfismo de seqüência. A análise da variabilidade haplotípica mostrou polimorfismo relativamente limitado, que resultou em 15 haplótipos, com diversidade genética total $\left(\mathrm{h}_{\mathrm{T}}\right)$ de 0,898 . Foi detectada a existência de estruturação genética significativa em distâncias de até $250 \mathrm{~m}$, o que indica dispersão de sementes restrita e confirma o padrão de organização espacial da variabilidade genética mostrado pela análise de DNA nuclear, o que evidencia isolamento por distância e a necessidade de manutenção de grandes áreas de floresta primária para garantir a sobrevivência de maior número de subpopulações.
\end{abstract}

Termos para indexação: conservação, estruturação genética espacial, maçaranduba, manejo, microssatélite, seqüenciamento.

\section{cpDNA variability in Manilkara huberi, a species under sustainable management in the Brazilian Amazon}

\begin{abstract}
The objective of this work was to evaluate the existence of matrilineal genetic structure in maçaranduba (Manilkara huberi). Evaluations were performed for 481 adult individuals of M. huberi, distributed in 200 hectares of a natural population in the Floresta Nacional do Tapajós, Belterra, PA, Brazil, and 88 plantules, based on nine chloroplast microsatellite loci and, of 96 individuals, selected randomly in the 200 ha area, it was carried out the sequencing of three intergenic regions from the cpDNA. No sequence polymorphism was detected. The analysis of the haplotypic variability showed a relatively low polymorphism, which resulted in 15 haplotypes, with total genetic diversity $\left(\mathrm{h}_{\mathrm{T}}\right)$ of 0.898 . Significant genetic structure until $250 \mathrm{~m}$ was detected, which indicates that seeds are restrictedly dispersed and confirms the pattern of spatial organization of the genetic variability, showed by the nuclear DNA analysis. This indicates isolation by distance and the need of maintenance of primary forest large areas to allow the surviving of a greater number of subpopulations.

Index terms: conservation, spatial genetic structure, maçaranduba, management, microsatellite, sequencing.
\end{abstract}

\section{Introdução}

A fragmentação florestal, em decorrência da exploração de recursos madeireiros, pode resultar em diminuição do potencial evolutivo das espécies, tornandoas isoladas e vulneráveis a eventos ambientais, demográficos e genéticos. Os efeitos genéticos associados à redução do tamanho populacional são primordialmente: a restrição no fluxo gênico, a deriva e o endocruzamento, o que geralmente resulta na diminuição da diversidade genética (Keller \& Waller, 2002).
Neste sentido, estudos de genética molecular têm se tornado parte integrante de diversos estudos de conservação (Haig, 1998). Em plantas, os estudos comparativos de genoma nuclear, de herança biparental e citoplasmática e de herança geralmente uniparental podem promover informações complementares (Williams et al., 2005) e até mesmo contrastantes a respeito da estrutura genética de populações naturais (McCauley, 1995).

Informações quanto ao grau de organização e dinâmica da variabilidade genética em populações de uma espécie são fundamentais para se delinearem 
estratégias eficientes de conservação e para a definição de estratégias de manejo sustentável. Entretanto, estudos desta natureza, para espécies arbóreas tropicais, ainda são poucos (Dayanandan et al., 1999; Collevatti, 2001; Cavers et al., 2003; Lemes et al., 2003; Cloutier et al., 2007; Silva et al., 2008).

A obtenção e a análise de dados discretos a partir de marcadores moleculares, com base em polimorfismo de DNA, têm se tornado uma forma eficiente de gerar informações para um grande número de indivíduos, populações e espécies. A evolução e a disponibilização de técnicas de biologia molecular têm contribuído significativamente para as investigações, cada vez mais detalhadas, da diversidade genética.

Tendo-se em vista a taxa de evolução lenta do genoma de cloroplasto (cpDNA), polimorfismos de haplótipos de microssatélites de cpDNA e de fragmentos de restrição ou seqüenciamento de regiões intergênicas têm sido tradicionalmente utilizados para investigações filogenéticas interespecíficas, pois se trata de uma molécula altamente conservada. As alterações ocorrem principalmente no tamanho do genoma, por meio de adição de novas sequiências ou deleção de seqüências existentes, geralmente pequenas, que envolvem de um a dez pares de base, localizados em regiões não codificadoras (Palmer, 1987). Vale ressaltar que regiões com maior grau de variação têm sido detectadas no genoma de cloroplasto, o que permite estudos de genética molecular intraespecíficos (Collevatti et al., 2003; Cloutier et al., 2005).

Estudos mostraram que a diversidade intraespecífica no cpDNA pode ser suficiente para estudos populacionais (Soltis et al., 1992). Weising \& Gardner (1999) desenvolveram uma série de marcadores microssatélites (SSR) de cloroplasto altamente conservados e universais para angiospermas. Taberlet et al. (1991) desenvolveram iniciadores universais que tornaram possível a amplificação via PCR e o seqüenciamento direto de duas regiões não codificadoras, o que tornou mais acessível o DNA de cloroplasto para estudos intraespecíficos.

Manilkara huberi (Ducke) A. Chev. é popularmente conhecida como maçaranduba ou maçaranduba verdadeira, atinge até $50 \mathrm{~m}$ de altura, possui tronco ereto e cilíndrico, com ritidoma marrom-acinzentado a escuro ou avermelhado, com fissuras profundas. Sua madeira é muito dura e resistente, e é a espécie da família Sapotaceae com madeira mais densa - entre 0,9 e $1,04 \mathrm{~g} \mathrm{~cm}^{-3}$ (Ferraz et al., 2004). Ocorre na Amazônia, principalmente em regiões de terra firme. Pode ser encontrada no Caribe, América Central e América do Sul e no Velho Mundo.

Esta é uma das espécies arbóreas amazônicas mais conhecidas e de maior ocorrência (10,5 indivíduos ha ${ }^{-1}$ de 0 a $140 \mathrm{~cm}$ de DAP), mesmo entre espécies do mesmo gênero (Embrapa, 2004). No grupo sucessional, pode ser considerada espécie-clímax, é hermafrodita, e algumas de suas populações florescem em intervalos de cinco anos, enquanto outras florescem anualmente. Suas flores são polinizadas por moscas e abelhas que apresentam vôo de médio alcance.

Um estudo anterior, a respeito da variabilidade genética autossômica de uma população de $M$. huberi, em floresta primária no Estado do Pará, indicou que a espécie apresenta elevada diversidade genética, embora com endocruzamento significativo ( $f=0,22$ ). Tem fluxo de pólen restrito (em torno de $49 \mathrm{~m}$ ), alta taxa de cruzamento entre parentes $(28 \%)$ e estruturação genética espacial (300 m) (Azevedo et al., 2007). A comparação do polimorfismo de sequiências nucleares e citoplasmáticas poderá auxiliar o entendimento das contribuições de dispersão de semente e pólen, na definição da estrutura genética de $M$. huberi. Esta análise comparativa permitirá fazer inferências sobre o passado da espécie, e definir se o nível e a distribuição espacial da diversidade genética observada atualmente representam um processo recente ou se são característicos da espécie em longo prazo.

A fim de confirmar a estrutura genética espacial da espécie e seu padrão de fluxo gênico, este estudo teve como objetivo investigar a existência de estruturação genética matrilinear de uma população de maçaranduba, com base na análise cpSSR, e no seqüenciamento de três regiões não codificadoras de cpDNA tipicamente polimórficas.

\section{Material e Métodos}

A população de $M$. huberi estudada localiza-se em 500 ha de floresta primária de terra firme da Amazônia brasileira, em área da Floresta Nacional do Tapajós (FLONA Tapajós), no km 83 da BR 163 da Rodovia Santarém-Cuiabá, Belterra, PA, a $2^{\circ} 51^{\prime} \mathrm{S}$ e $54^{\circ} 57^{\prime} \mathrm{W}$. Esta área é parte de uma PEI (Parcela de Estudos Intensivos), destinada a estudos ecológicos e genéticos, no âmbito do projeto Dendrogene, da Embrapa Amazônia Oriental (Kanashiro et al., 2002). No total, a amostragem populacional para os estudos genéticos constituiu-se de: 481 árvores com DAP a partir de $10 \mathrm{~cm}$, 
que representavam o total de árvores nesta categoria, em 200 dos 500 ha, e 88 regenerantes (DAP $<10 \mathrm{~cm}$ ), com alturas entre 13 e $190 \mathrm{~cm}$, distribuídos por toda a área de 500 ha. Os tecidos vegetais, utilizados para a extração de DNA, foram o câmbio caulinar das árvores e as folhas dos regenerantes.

A extração de DNA genômico e a genotipagem dos indivíduos foram realizadas no Laboratório de Genética Vegetal, da Embrapa Recursos Genéticos e Biotecnologia (Cenargen), Brasília, DF. A extração do DNA de câmbio e o de folhas foi realizada de acordo com o procedimento que utiliza o detergente CTAB (Doyle \& Doyle, 1987). A quantificação do DNA foi feita por comparação com DNA-padrão ( $\lambda$ DNA) em gel de agarose $1 \%$, corado com brometo de etídio. O DNA foi diluído para $1 \mathrm{ng} \mu \mathrm{L}^{-1}$.

Dez iniciadores SSR universais de cpDNA sintetizados com base no genoma de tabaco (Weising \& Gardner, 1999), todos de repetições de uma base, foram testados em reações de PCR com DNA de oito árvores de $M$. huberi, a fim de se obter a temperatura de anelamento $\left(\mathrm{T}_{\mathrm{a}}\right)$ ideal para cada par de iniciadores. Para isto, foram testadas temperaturas entre 50 e $62^{\circ} \mathrm{C}$. A reação de PCR consistiu da seguinte combinação de reagentes: $4 \mathrm{ng}$ de DNA, 1x de tampão de PCR (10 mM Tris-HCl, pH 8.3, $50 \mathrm{mM} \mathrm{KCl}$ ), $2 \mathrm{mM}$ de $\mathrm{MgCl}_{2}, 0,27 \mu \mathrm{M}$ de cada iniciador, $0,25 \mathrm{mM}$ de dNTP, $0,25 \mathrm{mg} \mathrm{mL}^{-1}$ de BSA, 1,3 U de Taq DNA polimerase e água ultrapura. Em cada par de iniciadores, o "forward" foi marcado com fluorescência para leitura em analisador automático de fragmento.
Para as reações de amplificação, foi utilizado o seguinte programa no termociclador: $94^{\circ} \mathrm{C}$ por $10 \mathrm{~min}$, 30 ciclos a $94^{\circ} \mathrm{C}$ por $1 \mathrm{~min}, \mathrm{~T}_{\mathrm{a}}$ (Tabela 1 ) por $1 \mathrm{~min}, 72^{\circ} \mathrm{C}$ por $1 \mathrm{~min}$ e uma extensão de $72^{\circ} \mathrm{C}$ por $10 \mathrm{~min}$. A temperatura de anelamento foi variada, de modo a aumentar a especificidade e eficiência de anelamento de cada par de iniciadores.

As reações de PCR foram realizadas separadamente para cada loco, diluídas (5:1), e sistemas multiplex com dois ou três locos foram montados com SSR marcados com diferentes fluorocromos, ou com um mesmo fluorocromo, porém com amplitudes alélicas distintas, os quais foram misturados a $10 \mu \mathrm{L}$ de um coquetel com formamida HiDi $(9 \mu \mathrm{L})$, marcador interno (ROX) $(0,25 \mu \mathrm{L})$ e água ultrapura $(0,75 \mu \mathrm{L})$. O marcador interno fluorescente utilizado foi o desenvolvido por Brondani \& Grattapaglia (2001). Esta mistura foi desnaturada por 5 min a $95^{\circ} \mathrm{C}$ e submetida à eletroforese.

Os produtos amplificados foram visualizados em gel de agarose a 3,5\%, corado com brometo de etídio. A partir dos resultados das amplificações, as detecções de polimorfismo foram realizadas em analisador automático de fragmentos, tendo-se utilizado o total de indivíduos amostrados: 481 adultos e 88 regenerantes. Para a determinação do tamanho exato do fragmento, que pode variar por possível escorregamento da Taq DNA polimerase e em consequiência de possíveis variações entre géis, dois indivíduos foram utilizados como controle, em todas as placas.

Tabela 1. Locos cpSSR utilizados nas análises da população de Manilkara huberi.

\begin{tabular}{|c|c|c|c|c|c|c|c|c|}
\hline Loco & Região & Seqüência dos iniciadores $\left(5^{\prime}-3^{\prime}\right)$ & Marcação & $\begin{array}{l}\text { Amplitude } \\
\text { alélica } \\
\text { esperada }^{(1)}\end{array}$ & $\begin{array}{c}\text { Amplitude } \\
\text { alélica } \\
\text { observada }\end{array}$ & SSR & $\mathrm{T}_{\mathrm{a}}\left({ }^{\circ} \mathrm{C}\right)$ & $\begin{array}{l}\mathrm{N}^{\mathrm{o}} \text { de } \\
\text { alelos }\end{array}$ \\
\hline ccmp01 & trnK intron & $\begin{array}{l}\text { F: CAGGTAAACTTCTCAACGGA } \\
\text { R: CCGAAGTCAAAAGAGCGATT }\end{array}$ & 6-FAM & $122-143$ & $136-144$ & $(\mathrm{~T})_{10}$ & 56 & 4 \\
\hline ccmp02 & $5^{\prime}$ to $\operatorname{trn} S$ & $\begin{array}{l}\text { F: GATCCCGGACGTAATCCTG } \\
\text { R: ATCGTACCGAGGGTTCGAAT }\end{array}$ & 6-FAM & $166-234$ & 209 & $(\mathrm{~A})_{11}$ & 62 & 1 \\
\hline ccmp03 & trnG intron & $\begin{array}{l}\text { F: CAGACCAAAAGCTGACATAG } \\
\text { R: GTTTCATTCGGCTCCTTTAT }\end{array}$ & HEX & $89-119$ & $114-116$ & $(\mathrm{~T})_{11}$ & 60 & 2 \\
\hline ccmp04 & atpF intron & $\begin{array}{l}\text { F: AATGCTGAATCGAYGACCTA } \\
\text { R: CCAAAATATTBGGAGGACTCT }\end{array}$ & NED & $115-220$ & 136 & $(\mathrm{~T})_{13}$ & 60 & 1 \\
\hline ccmp05 & $3^{\prime}$ to $\mathrm{rps} 2$ & $\begin{array}{l}\text { F: TGTTCCAATATCTTCTTGTCATTT } \\
\text { R: AGGTTCCATCGGAACAATTAT }\end{array}$ & 6-FAM & $77-145$ & $112-115$ & $(\mathrm{C})_{7}(\mathrm{~T})_{10}$ & 56 & 4 \\
\hline ccmp06 & ORF 77-ORF 82 & $\begin{array}{l}\text { F: CATGCATATGTAGAAAGCC } \\
\text { R: CATTACGTGCGACTATCTCC }\end{array}$ & 6-FAM & $93-111$ & 114 & $(\mathrm{~T})_{5} \mathrm{C}(\mathrm{T})_{17}$ & 62 & 1 \\
\hline ccmp07 & atpB-rbcL & $\begin{array}{l}\text { F: CAACATATACCACTGTCAAG } \\
\text { R: ACATCATTATTGTATACTCTTTC }\end{array}$ & NED & $129-151$ & $140-147$ & $(\mathrm{~A})_{13}$ & 56 & 3 \\
\hline ccmp09 & ORF 74b-psbB & $\begin{array}{l}\text { F: GGATTTGTACATATAGGACA } \\
\text { R: CTCAACTCTAAGAAATACTTG }\end{array}$ & HEX & $96-104$ & 98 & $(\mathrm{~T})_{11}$ & 50 & 1 \\
\hline ccmp10 & rpl2-rps19 & $\begin{array}{l}\text { F: TTTTTTTTTAGTGAACGTGTCA } \\
\text { R: TTCGTCGDCGTAGTAAATAG }\end{array}$ & HEX & $91-300$ & 105 & $(\mathrm{~T})_{14}$ & 56 & 1 \\
\hline
\end{tabular}

(1)Weising \& Gardner (1999). 
Para as análises via seqüenciamento de três regiões não codificadoras de cpDNA(Taberlet et al., 1991; Young et al., 1991), foram selecionados aleatoriamente 96 indivíduos de M. huberi, distribuídos em 200 ha na área da FLONA Tapajós. As regiões seqüenciadas foram: o segmento amplificado com o par de iniciadores $\mathrm{cpC}$ e cpD, tendo-se amplificado o íntron do gene trnL (UAA); o segmento amplificado com o par de iniciadores $\mathrm{cpE}$ e $\mathrm{cpF}$ que amplifica o espaço intergênico entre o éxon $\operatorname{trn} L$ (UAA) e $\operatorname{trnF}$ (GAA) (Taberlet et al., 1991); e o segmento da região ITS (internal transcribed space) que codifica a região $16 \mathrm{~S}$ de ribossomo, região amplificada com o par de iniciadores $\mathrm{Y}_{1}$ e $\mathrm{Y}_{2}$ (Young et al., 1991).

Para as reações de PCR, foram utilizados $2 \mathrm{ng}$ de DNA, 1x de tampão de PCR (10 mM Tris-HCl, pH 8.3, $50 \mathrm{mM} \mathrm{KCl}$ ), $2 \mathrm{mM}$ de $\mathrm{MgCl}_{2}, 0,2 \mathrm{mM}$ de cada dNTP, $0,2 \mathrm{mg} \mathrm{mL}^{-1}$ de BSA, $0,2 \mu \mathrm{M}$ de cada iniciador, $1 \mathrm{U}$ de Taq polimerase e água ultrapura estéril, para um volume final de $10 \mu \mathrm{L}$. Para as amplificações, foi utilizado o seguinte programa: $94^{\circ} \mathrm{C}$ por $5 \mathrm{~min}, 25$ ciclos a $94^{\circ} \mathrm{C}$ $1 \mathrm{~min}, 62^{\circ} \mathrm{C}$ por $1 \mathrm{~min}, 72^{\circ} \mathrm{C}$ por $30 \mathrm{~s}$, e uma extensão de $72^{\circ} \mathrm{C}$ por 2 min. Para a confirmação e quantificação da amplificação, $5 \mu \mathrm{L}$ da reação foram aplicados em gel de agarose a $1,5 \%$, corado com brometo de etídio $\left(1 \mathrm{mg} \mathrm{mL}^{-1}\right)$.

Para as reações de seqüenciamento, o produto de PCR foi purificado com o uso de exonuclease I e SAP ( $0,25 \mathrm{U}$ de cada enzima em $5 \mu \mathrm{L}$ de reação), por 1 hora a $37^{\circ} \mathrm{C}$. Após esse tempo, a atividade enzimática foi neutralizada, tendo-se exposto a reação a $80^{\circ} \mathrm{C}$ por $30 \mathrm{~min}$. Para as reações de seqüienciamento, foi utilizado o kit da Applied Biosystems (BigDye terminator v3.1) e iniciadores citados acima. Para cada reação de seqüenciamento de $10 \mu \mathrm{L}$, foram utilizados $20 \mathrm{ng}$ de DNA (produto da PCR), 1,6 $\mu \mathrm{M}$ de iniciador "forward" ou "reverse", $1 \mu \mathrm{L}$ da solução pré-mix do kit de seqüenciamento, $2 \mu \mathrm{L}$ de tampão "save money" e água ultrapura. A reação de seqüenciamento foi realizada de acordo com o programa: $94^{\circ} \mathrm{C}$ por $2 \mathrm{~min}, 30$ ciclos a $94^{\circ} \mathrm{C} 10 \mathrm{~s}, 50^{\circ} \mathrm{C}$ por $10 \mathrm{~s}, 60^{\circ} \mathrm{C}$ por $4 \mathrm{~min}$. A eletroforese das amostras foi realizada em analisador automático de fragmento. O protocolo de purificação da reação de seqüenciamento utilizado foi de precipitação por Etanol/ EDTA, proposto pelo fabricante (Applied Biosystems BigDye terminator v3.1).

Os locos cpSSR foram analisados quanto ao número de alelos por loco e número total de haplótipos únicos dentro da população.
A diversidade genética populacional $\left(\mathrm{h}_{\mathrm{T}}\right)$ foi calculada com o programa Permut (Pons \& Petit, 1996). As coordenadas geográficas dos indivíduos foram registradas com o uso de GPS, e as estimativas de estruturação genética espacial foram obtidas por meio de cálculo do índice $I$ de Moran (Sokal \& Oden, 1978). Para isso, todos os possíveis pares de árvores foram considerados como um conjunto e foram acessados para cada uma das 19 classes de distâncias pré-definidas. A significância total do correlograma foi testada pelos critérios de Bonferroni. As análises de autocorrelação espacial e os testes foram realizados com o programa SGS (Degen et al., 2003).

Os resultados obtidos foram confirmados com o programa SPAGeDi versão 1.1 (Hardy \& Vekemans, 2002), que calcula o coeficiente de coancestria $\left(\theta_{\mathrm{xy}}\right)$ entre pares de árvores. Este coeficiente foi estimado para dez classes de distâncias estabelecidas, conforme Loiselle et al. (1995).

As análises dos produtos de seqüenciamento foram realizadas com o programa BioEdit. As seqüências de 96 indivíduos adultos foram alinhadas e, nos casos onde variação de sequiência (deleção, inserção ou substituição) foi detectada, duas novas reações de seqüenciamento foram realizadas, para confirmação do polimorfismo.

\section{Resultados e Discussão}

Entre os dez locos cpSSR utilizados nas análises preliminares, apenas um (ccmp 08) não amplificou fragmentos de fácil interpretação. As temperaturas de anelamento ideais, definidas para cada loco, variaram entre 50 e $62^{\circ} \mathrm{C}$ (Tabela 1). Nas análises conduzidas com vistas à detecção de polimorfismo intraespecífico, seis locos não apresentaram variação haplotípica. O número de alelos por loco polimórfico variou de dois a quatro. Foram observados somente 15 haplótipos diferentes, dentro da população adulta composta por 481 indivíduos. Um dos haplótipos apresentou freqüência de 60\%, e quatro haplótipos foram observados somente em um indivíduo (Tabela 2).

Oito haplótipos foram identificados entre os regenerantes, dos quais o mais freqüente coincidiu com o mais freqüente na população adulta (Tabela 2), e dois não foram identificados na população adulta, o que era passível de ocorrer, uma vez que a área de amostragem dos regenerantes era maior (500 ha), em relação aos adultos (200 ha). A diversidade genética total $\left(\mathrm{h}_{\mathrm{T}}\right)$ da 
geração de adultos foi de $0,898 \pm 0,0126$, semelhante ao encontrado por Martins et al. (2006), em todas as populações estudadas de Solanum lycocarpum. A média de diferença entre os 15 haplótipos encontrados foi de 3,52, semelhante ao encontrado para Carapa guianensis (Cloutier et al., 2005), com base em marcadores CAPS, em cerca de 50 indivíduos provenientes de diferentes locais. A diversidade genética total $\left(\mathrm{h}_{\mathrm{T}}\right)$ dos 94 regenerantes, foi de $0,986 \pm 0,0019$.

A análise de correlação genética espacial (Figura 1) detectou, por meio de cálculos com o índice $I$ de Moran, a presença de estruturação até a distância de aproximadamente $250 \mathrm{~m}$, limite até o qual valores positivos e significativos foram estimados para I (IC 95\%), o que sugere que árvores próximas sejam geneticamente relacionadas por ancestral comum, provavelmente pais, filhos e irmãos. Foi observada diminuição contínua na autocorrelação que, a partir de $1.900 \mathrm{~m}$, apresentou valores negativos significativos, o que indica que árvores espacialmente distantes entre si tendem a não ser geneticamente relacionadas.

O histograma do coeficiente de coancestria (Loiselle et al., 1995) entre os genótipos de M. huberi, obtido com uso do programa SPAGeDi, também evidenciou estrutura genética espacial significativa até uma distância de aproximadamente $300 \mathrm{~m}$ (Figura 1), o que indica dispersão de sementes restrita a esse espaço. Foram detectados valores negativos significativos, a partir de cerca de $1.900 \mathrm{~m}$, a julgar pelo intervalo de confiança a 95\% do teste de reamostragem, o que corrobora o resultado obtido pelo índice $I$ de Moran.

Tabela 2. Distribuição das frequiências haplotípicas das duas gerações analisadas.

\begin{tabular}{ccc}
\hline Haplótipo & \multicolumn{2}{c}{ Freqüência $(\%)$} \\
\cline { 2 - 3 } & Adultos & Regenerantes \\
\hline 1 & 0,208 & 0,000 \\
2 & 0,208 & 0,000 \\
3 & 0,832 & 0,000 \\
4 & 0,208 & 0,000 \\
5 & 1,455 & 0,000 \\
6 & 0,624 & 0,000 \\
7 & 4,574 & 0,000 \\
8 & 8,316 & 5,682 \\
9 & 4,574 & 0,000 \\
10 & 15,593 & 23,864 \\
11 & 60,083 & 36,364 \\
12 & 2,911 & 13,636 \\
13 & 1,040 & 5,682 \\
14 & 0,208 & 6,818 \\
15 & 0,624 & 0,000 \\
16 & 0,000 & 2,273 \\
17 & 0,000 & 5,682 \\
\hline
\end{tabular}

As amplificações das regiões não codificadoras, com base nos pares de iniciadores cpC-cpD, cpE-cpF e $\mathrm{Y}_{1}-\mathrm{Y}_{2}$, geraram fragmentos de 525,362 e $260 \mathrm{pb}$, respectivamente. Polimorfismos de sequiência do tipo pontuais, como pequenas inserções ou deleções de até três bases e substituições de uma base, foram encontrados nas três regiões seqüenciadas, entretanto, sempre no final das sequiências, onde a qualidade do seqüenciamento é visivelmente baixa. Com o objetivo de confirmar os raros potenciais polimorfismos observados, todos os segmentos foram re-seqüenciados nos dois sentidos, "forward" e "reverse". Em nenhum caso, o polimorfismo observado inicialmente foi de fato confirmado, de modo que nenhuma variação de sequiência foi detectada por meio desta análise. A ausência de polimorfismo intrapopulacional era de certa forma esperado, tendo-se em vista a herança matrilínea e a taxa lenta de evolução do cpDNA. Variabilidade de seqüência no cpDNA é tipicamente observada, ao se analisarem indivíduos de diferentes populações, como o observado nas análises de Caryocar brasiliense (Collevatti et al., 2003), cujos indivíduos estudados eram provenientes de sete Estados brasileiros, portanto, distribuídos em populações distantes entre si em escala geográfica.

Nos últimos anos, o DNA plastidial tem sido utilizado com maior freqüência em estudos de genética de populações, especialmente em razão de sua herança tipicamente uniparental, modo de evolução (clonal) e baixa taxa de mutação. Grande parte dos estudos tem se baseado no método de PCR-RFLP, com base em iniciadores universais que permitem a análise de toda a molécula de cpDNA (Caron et al., 2000; Fineschi et al., 2000; Prentice et al., 2003; Oliver et al., 2006). Entretanto, novos estudos vêm surgindo, os quais têm se baseado em análises de polimorfismos de cpSSR universais ou seqüenciamento de regiões intergênicas (Collevatti et al., 2003; Lian et al., 2003; Lira et al., 2003; Martins et al., 2006; McGrath et al., 2007). Em razão de ser uma molécula altamente conservada entre as espécies de angiospermas, o DNA plastidial permite essa utilização em nível universal, e não é necessário, como no caso de DNA nuclear, que se isolem seqüências específicas de SSR.

Apesar de este trabalho contemplar apenas uma população, entretanto de ampla abrangência, os resultados encontrados são significativos, e foi possível inferir-se a respeito de um padrão geográfico de variação haplotípica. Os resultados obtidos nas análises com 
cpSSR confirmam os obtidos em estudos prévios com SSR nuclear, que indicam a presença de estruturação genética espacial, e que a população estudada é formada por subpopulações, resultantes de fluxo gênico restrito.
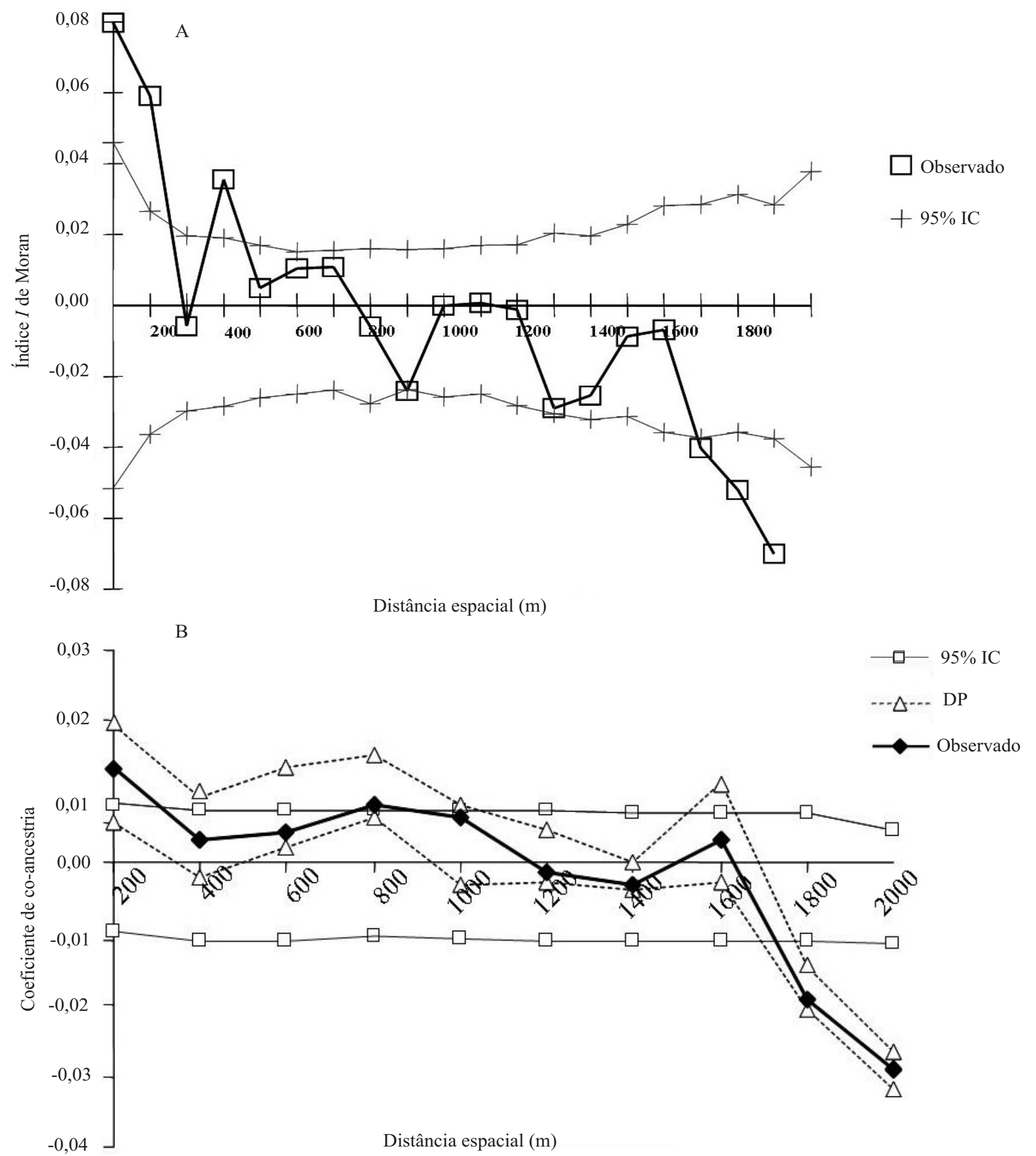

Figura 1. A, correlograma do índice $I$ de Moran, para 19 classes de distância, na população natural de Manilkara huberi; B, histograma do coeficiente de coancestria, de acordo com Loiselle et al. (1995), para 10 classes de distância, na população natural de M. huberi. 
Resultados semelhantes foram encontrados para outras espécies de regiões tropicais (Caron et al., 2000; Collevatti et al., 2003; Martins et al., 2006). Espera-se que, nas regiões tropicais, a distribuição geográfica do polimorfismo de cpDNA seja mais complexa do que no continente europeu, uma vez que, nos trópicos, as zonas de refúgio durante as glaciações foram caracterizadas por pequenas áreas de ampla distribuição (Prance, 1982). Vale ressaltar ainda que, apesar de se ter como certa a herança materna do DNA plastidial em angiospermas (Byrne et al., 1993), algumas exceções são passíveis de ocorrer (Ellis et al., 2008), de modo que uma eventual herança paterna possa ocorrer e influenciar a diversidade haplotípica intraespecífica e levar, conseqüentemente, à inferência errônea de múltiplas linhagens maternas. Entretanto, este não deve ser o caso de M. huberi, uma vez que polimorfismos foram detectados somente em regiões de cpSSR que são repetitivas, mais sujeitas à mutações e, portanto, devem representar mutações mais recentes, o que leva a concluir que a população teve origem a partir de uma ou poucas linhagens maternas, já que não foi detectado polimorfismo na análise via seqüenciamento. Ainda assim, caso a herança paterna tenha ocorrido, mesmo que de forma rara, seria necessária a análise de um grande número de transmissões de cpDNA entre pais e filhos para excluirse categoricamente a possibilidade de herança paterna.

Como $M$. huberi é uma espécie de ampla distribuição, este padrão de subestruturação populacional pode ser resultado de um fluxo gênico, de acordo com o modelo de isolamento por distância. Este padrão pode ter surgido em razão da perda de dispersores eficientes de semente, o que levou à limitação da eficiência de dispersão, fez com que as sementes se mantivessem próximas às árvores maternas e fossem dispersas principalmente pela gravidade, o que causou o isolamento e a estruturação de demes de plantas que compartilham a mesma linhagem materna. Atualmente, a dispersão ocorre principalmente pela gravidade, mas alguns macacos são também dispersores conhecidos, como Saimiri sciureus (Camizão et al., 2002).

\section{Conclusões}

1. O padrão de estruturação da população de Manilkara huberi, em subpopulações de indivíduos genética e espacialmente mais próximos entre si, confirma o resultado do estudo de DNA nuclear que indicou a subestruturação espacial dos genótipos.
2. A estruturação genética espacial é característica da espécie e indica padrão de fluxo gênico por isolamento por distância.

3. Grandes áreas contínuas de floresta primária devem ser preservadas, para se conservar a diversidade genética da espécie organizada em subpopulações geneticamente diferentes.

\section{Agradecimentos}

À equipe do Projeto Dendrogene, pelas coletas na FLONA Tapajós, PA, Brasil e pelo suporte técnicocientífico; ao Department for International Development (British Government), pelo apoio financeiro; ao Ian Thompson e ao Instituto Brasileiro de Meio Ambiente e dos Recursos Naturais e Renováveis.

\section{Referências}

AZEVEDO, V.C.R.; KANASHIRO, M.; CIAMPI, A.Y.; GRATTAPAGLIA, D. Genetic structure and mating system of Manilkara huberi (Ducke) A. Chev. a heavily logged Amazonian timber species. Journal of Heredity, v.98, p.646-654, 2007.

BRONDANI, R.P.V.; GRATTAPAGLIA, D. Cost-effective method to synthesize a fluorescent internal DNA standard for automated fragment sizing. Biotechniques, v.31, p.793-800, 2001.

BYRNE, M.; MORAN, G.F.; TIBBITS, W.N. Restriction map and maternal inheritance of chloroplast DNA in Eucalyptus nitens. Journal of Heredity, v.84, p.218-220, 1993.

CAMIZÃO, I.C.; CONTENTE, F.A.S. Distribuição espacial de três espécies arbóreas no fragmento florestal Bosque Rodrigues Alves Belém, PA. In: CONGRESSO BRASILEIRO DE SISTEMAS AGROFLORESTAIS, 4., 2002, Ilhéus, BA. Anais. Ilheus: Ceplac, 2002. p.1-4.

CARON, H.; DUMAS, S.; MARQUE, G.; MESSIER, C.; BANDOU, E.; PETIT, R.J.; KREMER, A. Spatial and temporal distribution of chloroplast DNA polymorphism in a tropical tree species. Molecular Ecology, v.9, p.1089-1098, 2000.

CAVERS, S.; NAVARRO, C.; LOWE, A.J. Chloroplast DNA phylogeography reveals colonization history of a neotropical tree, Cedrela odorata L., in Mesoamerica. Molecular Ecology, v.12, p.1451-1460, 2003.

CLOUTIER, D.; KANASHIRO, M.; CIAMPI, A.Y.; SCHOEN, D.J. Impact of selective logging on inbreeding and gene dispersal in an Amazonian tree population of Carapa guianensis Aubl. Molecular Ecology, v.16, p.797-809, 2007.

CLOUTIER, D.; PÓVOA, J.S.R.; PROCÓPIO, L.C.; LEÃO, N.V.M.; WADT, L.H. de O.; CIAMPI, A.Y.; SCHOEN, D.J. Chloroplast DNA variation of Carapa guianensis in the Amazon basin. Silvae Genetica, v.54, p.274, 2005.

COLLEVATTI, R.G.; GRATTAPAGLIA, D.; HAY, J.D. Evidences for multiple maternal lineages of Caryocar brasiliense populations 
in the Brazilian Cerrado based on the analysis of chloroplast DNA sequences and microsatellite haplotype variation. Molecular Ecology, v.12, p.105-115, 2003.

COLLEVATTI, R.G.; GRATTAPAGLIA, D.; HAY, J.D. High resolution microsatellite based analysis of the mating system allows the detection of significant biparental inbreeding in Caryocar brasiliense, an endangered tropical tree species. Heredity, v.86, p.6067, 2001.

DAYANANDAN, S.; DOLE, J.; BAWA, J.; KESSELI, R. Population structure delineated with microsatellite markers in fragmented populations of a tropical tree, Carapa guianensis (Meliaceae). Molecular Ecology, v.8, p.1585-1592, 1999.

DEGEN, B.; PETIT, R.; KREMER, A. SGS - Spatial Genetic Software: a computer program for analysis of spatial genetic and phenotypic structures of individuals and populations. Journal of Heredity, v.92, p.447-448, 2001.

DOYLE, J.J.; DOYLE, J.L. Isolation of plant DNA from fresh tissue. Focus, v.12, p.13-15, 1987.

ELLIS, J.R.; BENTLEY, K.E.; McCAULEY, D.E. Detection of rare paternal chloroplast inheritance in controlled crosses of the endangered sunflower Helianthus verticillatus. Heredity, v.100, p.574-580, 2008.

EMBRAPA. Maçaranduba Manilkara huberi. Belém: Embrapa Amazônia Oriental, 2004. (Projeto Dendrogene. Espécies Arbóreas da Amazônia, 4).

FERRAZ, I.D.K.; LEAL-FILHO, N.; IMAKAWA, A.M.; VARELA, V.P.; PINA-RODRIGUES, F.C.M. Características básicas para um agrupamento ecológico preliminar de espécies madeireiras da floresta de terra firme da Amazônia Central. Acta Amazonica, v.34, p.621633, 2004.

FINESCHI, S.; TAURCHINI, D.; VILLANI, F.; VENDRAMIN, G.G. Chloroplast DNA polymorphism reveals little geographical structure in Castanea sativa Mill. (Fagaceae) throughout Southern European countries. Molecular Ecology, v.9, p.1495-1503, 2000.

HAIG, S.M. Molecular contributions to conservation. Ecology, v.79, p.413-425, 1998.

HARDY, O.J.; VEKEMANS, X. SPAGeDi: a versatile computer program to analyse spatial genetic structure at the individual or population levels. Molecular Ecology Notes, v.2, p.618-620, 2002.

KANASHIRO, M.; THOMPSON, I.S.; YARED, J.A.G.; LOVELESS, M.D.; COVENTRY, P.; MARTINS-DA-SILVA, R.C.V.; DEGEN, B.; AMARAL, W. Improving conservation values of managed forests: the Dendrogene Project in the Brazilian Amazon. Unasylva, v.53, p.25-33, 2002.

KELLER, L.F.; WALLER, D.M. Inbreeding effects in wild populations. Trends in Ecology and Evolution, v.17, p.230-241, 2002.

LEMES, M.R.; GRIBEL, R.; PROCTOR, J.; GRATTAPAGLIA, D. Population genetic structure of mahogany (Swietenia macrophylla King, Meliaceae) across the Brazilian Amazon, based on variation at microsatellite loci: implications for conservation. Molecular Ecology, v.12, p.2875-2883, 2003.

LIAN, C.; OISHI, R.; MIYACHITA, N.; NARA, K.; NAKAYA, H.; WU, B.; ZHOU, Z.; HOGETSU, T. Genetic structure and reproduction dynamics of Salix reinii during primary succession on Mount Fuji, as revealed by nuclear and chloroplast microsatellite analysis. Molecular Ecology, v.12, p.609-618, 2003.

LIRA, C.F.; CARDOSO, S.R.S.; FERREIRA, P.C.G.; CARDOSO, M.A.; PROVAN, J. Long-term population isolation in the endangered tropical tree species Caesalpinia echinata Lam. revealed by chloroplast microsatellites. Molecular Ecology, v.12, p.3219-3225, 2003.

LOISELLE, B.A.; SORK, V.L.; NASON, J.; GRAHAM, C. Spatial genetic structure of a tropical understory shrub, Psychotria officinalis (Rubiaceae). American Journal of Botany, v.82, p.1420-1425, 1995.

MARTINS, K.; CHAVES, L.J.; BUSO, G.S.C.; KAGEYAMA, P.Y. Mating system and fine-scale spatial genetic structure of Solanum lycocarpum St.Hil. (Solanaceae) in the Brazilian Cerrado. Conservation Genetics, v.7, p.957-969, 2006.

McCAULEY, D.E. The use of chloroplast DNA polymorphism in studies of gene flow in plants. Trends in Ecology and Evolution, v.10, p.198-202, 1995.

McGRATH, S.; HODKINSON, T.R.; BARTH, S. Extremely high cytoplasmic diversity in natural and breeding populations of Lolium (Poaceae). Heredity, v.99, p.531-544, 2007.

OLIVER, C.; HOLLINGSWORTH, P.M.; GORNALL, R.J. Chloroplast DNA phylogeography of the arctic-montane species Saxifraga hirculus (Saxifragaceae). Heredity, v.96, p.222-231, 2006.

PALMER, J.D. Chloroplast DNA evolution and biosystematic uses of chloroplast DNA variation. American Naturalist, v.130, p.629, 1987. (Suplemento)

PONS, O.; PETIT, R.J. Measuring and testing genetic differentiation with ordered versus unordered alleles. Genetics, v.144, p.1237$1245,1996$.

PRANCE, G.T. Forest refuges: evidence from woody angiosperms. In: PRANCE, G.T. Biological diversification in the tropics. New York: Columbia University Press, 1982. p.137-158.

PRENTICE, H.C.; MALM, J.U.; MATEU-ANDRÉS, I.; SEGARRA-MORAGUES, J. Allozyme and chloroplast DNA variation in island and mainland populations of the rare Spanish endemic, Silene hifacensis (Caryophyllaceae). Conservation Genetics, v.4, p.543-555, 2003.

SILVA, M.B.; KANASHIRO, M.; CIAMPI, A.Y.; THOMPSON, I.; SEBBENN, A.M. Genetic effects of selective logging and pollen gene flow in a low-density population of the dioecious tropical tree Bagassa guianensis in the Brazilian Amazon. Forest Ecology and Management, v.255, p.1548-1558, 2008.

SOKAL, R.R.; ODEN, N.L. Spatial autocorrelation in biology. I. Methodology. Biological Journal of the Linnean Society, v.10, p.199-228, 1978. 
SOLTIS, D.E.; SOLTIS, P.S.; MILLIGAN, B.G. Intraspecific chloroplast DNA variation: systematic and phylogenetic implications. In: SOLTIS, P.S.; SOLTIS, D.E.; DOYLE, J.J. (Ed.). Molecular plant sistematics. New York: Chapman and Hall, 1992. p.117-150.

TABERLET, P.; GIELLY, L.; PAUTOU, G.; BOUVET, J. Universal primers for amplification of three non-coding regions of chloroplast DNA. Plant Molecular Biology, v.17, p.1105-1109, 1991.

WEISING, K.; GARDNER, R.C. A set of conserved PCR primers for the analysis of simple sequence repeat polymorphisms in chloroplast genomes of dicotyledonous angiosperms. Genome, v.42, p.9-19, 1999.

WILLIAMS, D.A.; OVERHOLT, W.A.; CUDA, J.P.; HUGHES, C.R. Chloroplast and microsatellite DNA diversities reveal the introduction history of Brazilian peppertree (Schinus terebinthifolius) in Florida. Molecular Ecology, v.14, p.3643-3656, 2005.

YOUNG, J.P.W.; DOWNER, H.L.; EARDLY, B.D. Phylogeny of the phototrophic Rhizobium strain BTAil by polymerase chain reaction-based sequencing of a $16 \mathrm{~S}$ rRNA gene segment. Journal of Bacteriology, v.73, p.2271-2277, 1991.

Recebido em 18 de dezembro de 2007 e aprovado em 26 de junho de 2008 
